from the origin of the pole cells to the mature, functioning organ. This anatomical detail is extensively illustrated. But the text is also an essay in developmental genetics, for the advantage of Drosophila is that mutants are available which interfere with normal processes and thus provide comparative material for experimental study.

Not all the general problems of morphogenesis are subsumed in the ovary, but a large number are: from the origins of polarity in the undifferentiated larval rudiment, through the many problems of stem cells, the exact regulation of division of their products to form 16-cell cysts and the differentiation of all but one of these cells into polytene nurse cells, to cell interactions and to the hormonal initiation of egg production and the regulation of egg output. All of these are discussed, but only a few mutants affecting some morphogenetic events have so far been found and can be examined. This book should stimulate the search for more. Using female sterile mutants (fused, female sterile and narrow) it has been possible to show, for instance, that each gene affects the restriction of cystocyte division, leads to the development of "tumorous" cysts, and acts autonomously. King produces a molecular model to explain this, which he recognizes is too speculative but which may be a useful working hypothesis. Similarly, he uses crossover suppressor mutations to examine the cytology of the oocyte nucleus, and shows that synaptonemal complexes are not then formed. This leads to an extensive discussion of recombination, and to further models. The effects of other mutants influencing vitellogenesis, development of follicle colls and of nurse cells are also indicated, and the book concludes with a short section on interactions of the ovary with other organs. Unfortunately these interesting analyses throw little light on the major problem of relating the detailed events of ovogenesis to embryonic determination in this mosaic egg.

In some respects too much material is compressed into too little space, and the book is far too expensive for its size. But it is a mine of information, covering about 500 references, and it should stimulate further work, as intended. There is a comprehensive index.

JAMES H. SANG

\section{ORGANELLE DEVELOPMENT}

\section{Control of Organelle Development}

Edited by P. L. Miller. (Symposia of the Society for Experimental Biology, No. 24.) Pp. viii + 524. Published for the Company of Biologists on behalf of the Society for Experimental Biology. (Cambridge University: London, October 1970.) 140s.

Alimough the non-chromosomal transmission of mutations involving chloroplast and mitochondrial functions had been studied for many years, it is only in the past decade, following the discovery that these organelles contained DNA and were capable of incorporating labelled amino-acids into their proteins independently of the cytoplasmic ribosomal systems, that a combined assault by biochemists, cytologists and geneticists on the problem of organelle development has been sustained.

It is difficult to point to the major contributions made by individual authors in this volume because many contributors have attacked the problems across a broad front. Overall, however, a coherent picture of the influences involved in the assembly of chloroplasts and mitochondria emerges. Their DNA, RNA and protein synthesizing systems are shown to resemble the corresponding systems in bacteria and reinforce the idea, favoured by a number of contributors, that these organelles have evolved from endosymbiotic prokaryotes. It is made equally clear that the degree of autonomy of chloroplasts and mitochondria is limited and that nuclear genes provide considerable information for the structure of the organelles and control of their assembly. Even the nucleus enjoys only a limited autonomy for its activities are shown to be influenced by the status of the cytoplasm.

Three contributors describe their work on recombination of chloroplast and mitochondrial genes. Of particular interest in this respect is the suggestion by Slonimski and his co-workers that, in yeast, the tendency for mitochondrial genes to undergo recombination depends not only on their separation, but also on their distance from a polarity locus which may vary from strain to strain. This implies a kind of mitochondrial sexuality, possibly independent of the cell mating type.

On the whole, the contributions maintain the high standard set by previous symposia organized by the Society for Experimental Biology and the book provides a more comprehensive approach to the field of organelle development than has been previously achieved.

Peter A. Whittaker

\section{PLANT VARIETIES}

\section{Genetic Resources in Plants}

Their Exploration and Conservation. Edited by $\mathrm{O}$. $\mathrm{H}$. Frankel and E. Bennett. (IBP Handbook No. 11.) Pp. xxi 554. (Blackwell Scientific: Oxford and Edinburgh.) $100 \mathrm{~s}$

THIs book, published in the IBP Handbook Series as a guide for biologists participating in international programmes, includes the papers presented during an FAO/ IBP technical conference held in Rome in 1967. It is divided into six sections. The first deals with the evolution of cultivated plants and includes descriptions of the pattern of genetic variability and of adaptation in cultivated plant populations. This is an extremely useful section emphasizing important concepts and principles. This subject leads on to the tactics of plant exploration and to the ecological considerations involved. The third. section describes the methods of exploring variability in individual crops and forest tree species and is rather inadequate in that no crop is dealt with fully. Section four includes the evaluation and utilization of genetio resources, and chapter 37 by Krull and Borlaug stresses an important point that effective utilization of variability in breeding improvement depends on breeding to a well defined objective. The final sections, on documentation and conservation, contain information which is new. The methods suggested for the conservation of genetic resources include the management and provision of an inventory of wild communities or primitive cultivars, the mainten. ance of plant introduction collections at breeding stations, world seed banks and the development of composites or mass reservoirs of variability. Because there is no practical way in which plant material can be maintained with complete genetic integrity, any of these methods must be a compromise and the problems of maintenance of variability are clearly discussed by Allard in chapters 8 and 41. Although the conservation of variability is important it would be quite impossible to conserve all the variability that now exists and the plant breeder could never utilize all this variability. Effective utilization of variability by the plant breeder must be emphasized; so often genetic advance is not limited by variability but by the selection pressures to which the organism is subjected.

This book with its 554 pages and more than forty con. tributors is not recommended for consumption in one sitting but rather as a book to be dipped into like an encyclopaedia. As such, it provides a most useful source of information not available elsewhere; the editors and contributors have succeeded in stimulating thought and possibly action on this world wide problem of the con. servation of genetic resources in plants. A. M. Evans 